\title{
DEVELOPMENT AND VALIDATION OF A NOVEL STABILITY INDICATING RP-UPLC METHOD FOR SIMULTANEOUS DETERMINATION OF NIZATIDINE, METHYLPARABEN AND PROPYLPARABEN IN ORAL LIQUID PHARMACEUTICAL FORMULATION
}

\author{
Navneet Kumar*, Bhupendrasinh Vaghela and P. Sunil Reddy \\ Dr. Reddy's Laboratories Ltd., IPDO, Bachupally, Hyderabad-500072, A.P, India \\ D. Sangeetha \\ Department of Chemistry, S.A.S., V.I.T. University, Vellore - 632014, Tamilnadu, India
}

Recebido em 24/8/11; aceito em 12/10/11; publicado na web em 4/1/12

\begin{abstract}
A selective and accurate stability-indicating gradient reverse phase ultra performance liquid chromatographic method has been developed and validated for the simultaneous determination of nizatidine, methylparaben and propylparaben in pharmaceutical oral liquid formulation. The separation was achieved on Acquity UPLC ${ }^{\mathrm{TM}}$ HSS T3 $1.8 \mu \mathrm{m}$ column by using mobile phase containing a gradient mixture of solvent $\mathrm{A}\left(0.02 \mathrm{Mol} \mathrm{L}^{-1} \mathrm{KH}_{2} \mathrm{PO}_{4}, \mathrm{pH} 7.5\right)$ and $\mathrm{B}(60: 40 \mathrm{v} / \mathrm{v}$ mixture of methanol and acetonitrile) at flow rate of $0.4 \mathrm{~mL} \mathrm{~min}^{-1}$. Drug product was exposed to the stress conditions of oxidative, acid, base, hydrolytic, thermal and photolytic degradation. The developed method was validated as per international ICH guidelines with respect to specificity, linearity, accuracy, precision and robustness.
\end{abstract}

Keywords: nizatidine; stability-indicating; UPLC-UV.

\section{INTRODUCTION}

Nizatidine is a histamine H2-receptor anatagonist commonly used in the treatment of gastroesophageal reflux disease, duodenal and gastric ulceration. Its chemical designation is $\mathrm{N}-[2-[[[2-[$ (dimethylamino) methyl]-4-thiazoyl] thio]-N'-methyl-2-nitro-1,1-ethenediamine (Figure 1a). ${ }^{1}$ Nizatidine can be found in many pharmaceutical forms such as tablets, capsules, injections and oral liquids. Compared to tablet and capsule, liquid formulations favour a most rapid absorption of active substance. Liquid preparations are particularly suceptible to mocrobial growth because of the nature of their ingradtient. Such preparations require the presence of preservatives and antimicrobial agents, to prevent chemical alteration and degradation of drug substance.

(a)<smiles>CN/C(=C\[N+](=O)[O-])NCCSCc1csc(CN(C)C)n1</smiles>

(b)<smiles>COC(=O)c1ccc(O)cc1</smiles><smiles>CCCOC(=O)c1ccc(O)cc1</smiles>

Figure 1. Structures of (a) nizatidine, (b) methylparaben and (c) propylparaben

Paraben, a group of alkyl esters of $p$-hydroxybenzoic acid are widely used as antimicrobial preservatives in cosmetics, food and pharmaceutical products. ${ }^{2}$ The parabens are effective over a wide $\mathrm{pH}$ range and present a brod sprectrum of antimicobial activity, although they are most effective against yeast and molds. Methylparaben and

*e-mail: navneetrajpoot21@yahoo.com propylparaben have been used for the preservation of nizatidine oral solution (Figure 1b-c). The analysis of these preservatives in commercial pharmaceutical product is particularly important for both, quality assurance and consumer protection. Indian drugs and cosmetics act ${ }^{3}$ and International Conference on Harmonization $(\mathrm{ICH})^{4}$ guidance recommends that release and stability testing for preservative content should be performed and finished product self-life specification should also include identification test, preservative content and limits for antimicrobial preservative present. Therefore, the analysis of nizatidine into oral solution in combination with preservative is required and essential. Some liquid chromatography (LC) methods are available for the determination of nizatidine in biological fluids. ${ }^{5-8}$ Literature reported the HPLC analysis for famotidine, ranitidine, cimetidine and nizatidine in drug products and stability indicating LC method for nizatidine and its impurities. ${ }^{9}{ }^{10}$ Nizatidine monograph is also listed in United States Pharmacopoiea (USP) ${ }^{11}$ and European Pharmacopoeia (Eur. Ph.). ${ }^{12}$ USP monograph describes a chromatographic assay method for nizatidine with a runtime of $40 \mathrm{~min}$ and Ph.Eur. describes assay method for nizatidine with a runtime of 25 min. No pharmacopoeial monograph is available for nizatidine oral solution. Several analytical procedures have been reported for the determination of methylparaben and propylparaben seperately or in combination with the other drugs by LC and other techniques. ${ }^{13-17}$ These methods may not be suitable for simultaneous determination of nizatidine, methylparaben and propylparaben together in one chromatographic run.

To the best of our knowledge, there is no stability indicating LC method reported for the estimation of nizatidine, methylparaben and propylparaben in oral liquid formulation. Therefore, attempts were made in this study to develop a fast, sensitive, selective, robust and stability indicating reverse phase ultra-performance liquid chromatography (UPLC) method for the simultaneous determination of nizatidine, methylpraben and propylparaben in oral liquid formulation. The developed LC method was validated with respect to specificity, linearity, precision, accuracy and robustness. Force degradation studies were performed on the placebo and drug products. Developed method separates all degradation products from nizatidine, methylparaben and 
propylparaben, and exhibits stability indicating nature. These studies were performed in accordance with established ICH guidelines. ${ }^{18,19}$ Developed method can be used for routine analysis of production samples and stability testing of the nizatidine oral solution to ensure the quality of the product.

\section{EXPERIMENTAL}

\section{Reagents and chemicals}

Nizatidine standard (99.6\% pure) and oral solution was supplied by Dr. Reddy's laboratories limited, Hyderabad, India. Methylparaben (99.9\% pure) and propylparaben (100\% pure) were procured from United State Pharmacopoeia (USP). The high performance liquid chromatography (HPLC) grade acetonitrile and methanol; and analytical grade potassium di-hydrogen ortho-phosphate and sodium hydroxide were purchased from Merck, Mumbai, India. High purity water was prepared by using Millipore Milli-Q Plus water purification system (Millipore, Milford, MA, USA).

\section{Instrumentation and chromatographic conditions}

The chromatography analysis was performed using Waters Acquity ${ }^{\mathrm{TM}}$ UPLC separation module (Waters Corporation, Milford, USA) equipped with photo diode array (PDA) detector, binary solvent manager and auto sampler system. The output signal was monitored and processed using Empower 2 software. The separation was achieved on Acquity UPLC ${ }^{\mathrm{TM}}$ HSS T3 (100 x $\left.2.1 \mathrm{~mm}\right)$ $1.8 \mu \mathrm{m}$ column (Waters Corporation, Milford, USA) with mobile phase containing a gradient mixture of solvent A $\left(0.02 \mathrm{Mol} \mathrm{L}^{-1}\right.$ potassium dihydrogen ortho-phosphate, $\mathrm{pH}$ adjusted to 7.5 with sodium hydroxide solution) and B (60:40 v/v mixture of methanol and acetonitrile) at flow rate of $0.4 \mathrm{~mL} \mathrm{~min}^{-1}$. The gradient program (Time (min)/\%B) was set 0/20, 1/25, 5/37, 7/55, 8/65, 8.5/65, 8.6/20 and $10 / 20$. The column oven temperature was maintained at $35^{\circ} \mathrm{C}$ and eluted compounds were monitored at the wavelength of 254 $\mathrm{nm}$. The sample injection volume was $4 \mu \mathrm{L}$. Cintex digital water bath was used for hydrolysis studies. Photo-stability studies were carried out in photo-stability chamber (Sanyo, Leicestershire, UK). Thermal stability studies were performed in a dry air oven (Cintex, Mumbai, India). The $\mathrm{pH}$ of the solutions was measured by a $\mathrm{pH}$ meter (Mettler-Toledo, Switzerland).

\section{Preparation of standard solution}

Solvent A and methanol in the ratio of $80: 20 \mathrm{v} / \mathrm{v}$ was used as diluent. A stock solution of nizatidine $\left(0.6 \mathrm{mg} \mathrm{mL}^{-1}\right)$ was prepared by dissolving an appropriate drug in diluent. The stock solutions of methylparaben $\left(0.72 \mathrm{mg} \mathrm{mL}^{-1}\right)$ and propylparaben $\left(0.2 \mathrm{mg} \mathrm{mL}^{-1}\right)$ were prepared in methanol, separately. A mixed stock solution containing $72 \mu \mathrm{g} \mathrm{mL}-1$ methylparaben and $8 \mu \mathrm{g} \mathrm{mL}^{-1}$ of propylparaben was prepared from their respective stock solutions. Working standard solution was prepared in diluent from mixing above stock solutions of nizatidine, methylparaben and propylparaben with final concentration of $120,14.4$ and $1.6 \mu \mathrm{g} \mathrm{mL}^{-1}$, respectively.

Calibration curves were prepared by diluting stock solutions of nizatidine, methylparaben and propylparaben with diluent to get a series of solutions containing final concentrations of $0.34,11.9,59.6$, 89.5, 119.3, 137.2 and $178.9 \mu \mathrm{g} \mathrm{mL}^{-1}$ for nizatidine; and $0.11,1.45$, $7.26,10.9,14.5,16.7$ and $21.8 \mu \mathrm{g} \mathrm{mL}^{-1}$ for methylparaben; and 0.07 , $0.16,0.82,1.22,1.63,1.88$ and $2.45 \mu \mathrm{g} \mathrm{mL} \mathrm{m}^{-1}$ for propylparaben. A graph was plotted as concentration of analyte versus peak area response and found to be linear for all three analytes.

\section{Preparation of sample solution}

An amount (about $2 \mathrm{~g}$ ) of oral solution equivalent to $30 \mathrm{mg}$ nizatidine was transferred into $50 \mathrm{~mL}$ volumetric flask, added $35 \mathrm{~mL}$ of diluent and ultrasonicated for $10 \mathrm{~min}$, and then diluted to volume with diluent. $5 \mathrm{~mL}$ of this solution was diluted to $25 \mathrm{~mL}$ with diluent, to give a solution containing $120 \mu \mathrm{g} \mathrm{mL}^{-1}$ of nizatidine, $14.4 \mu \mathrm{g} \mathrm{mL}^{-1}$ of methylparaben and $1.6 \mu \mathrm{g} \mathrm{mL}^{-1}$ of propylparaben (Figure $2 \mathrm{a}$ ).

\section{RESULTS AND DISCUSSION}

\section{Method development and optimization}

The main objective of the chromatographic method was to separate and quantitate niziatidine, methylparaben and propylparaben in presence other placebo components like flavor agents and colors. An isocratic method employed using $0.02 \mathrm{Mol} \mathrm{L}^{-1}$ potassium dihydrogen ortho-phosphate ( $\mathrm{pH} 3.0$ ) and acetonitrile in the ratio of 70:30 as mobile phase, Acquity UPLC ${ }^{\circledR}$ BEH Shield $(150$ x $2.1 \mathrm{~mm}) 1.7 \mu \mathrm{m}$ column with flow rate of $0.4 \mathrm{~mL} \mathrm{~min}^{-1}$ on UPLC equipped with photo diode array detector. Nizatidine peak was eluted too early along with placebo peaks and propylparaben retained strongly. To retain and separate nizatidine from placebo peaks and reduce the run time an attempt was made with gradient elution with mobile phase $0.02 \mathrm{Mol} \mathrm{L}^{-1}$ potassium dihydrogen ortho-phosphate buffer ( $\mathrm{pH} 3.5)$ as solvent-A and solvent-B (mixture of acetonitrile and water in the ratio of 80:20 v/v). Nizatidine was retained but many placebo peaks co-eluted with nizatidine. To resolve the nizatidine from placebo, solvent A modified to $0.15 \mathrm{Mol} \mathrm{L}^{-1}$ ammonium formate having $\mathrm{pH} 5.5$ and Acquity UPLC ${ }^{\mathrm{TM}} \mathrm{HSS}$ T3 (100 x $2.1 \mathrm{~mm}$ ) $1.8 \mu \mathrm{m}$ selected for separation. But satisfactory resolution was not achieved between nizatidine and placebo peaks. To achieve good separation, solvent A modified to $0.02 \mathrm{Mol} \mathrm{L}^{-1}$ potassium dihydrogen ortho-phosphate buffer ( $\mathrm{pH} 7.5)$ and solvent $\mathrm{B}$ modified to a mixture of methanol and acetonitrile in the ratio of 60:40 (v/v), respectively. On the optimization of gradient program, nizatidine, methylparaben and propylparaben peaks ware well resolved form each other and placebo peaks with a shorter run time. Based on these experiments, the final optimized conditions are described below.

Acquity UPLC ${ }^{\mathrm{TM}}$ HSS T3 $(100 \times 2.1 \mathrm{~mm}) 1.8 \mu \mathrm{m}$ was used as the stationary phase. The mobile phase A consist of $0.02 \mathrm{Mol} \mathrm{L}^{-1}$ potassium dihydrogen ortho-phosphate having $\mathrm{pH} 7.5$ and mobile phase $\mathrm{B}$ contained a mixture of methanol and acetonitrile in the ratio of $60: 40(\mathrm{v} / \mathrm{v})$. The flow rate was $0.4 \mathrm{~mL} \mathrm{~min}^{-1}$ with a gradient program of (time (min)/ \%B) 0/20, 1/25, 5/37, 7/55, 8/65, 8.5/65, 8.6/20 and $10 / 20$. The column temperature was maintained at $35^{\circ} \mathrm{C}$ and detection was monitored at $254 \mathrm{~nm}$. The injection volume was $4 \mu \mathrm{L}$. The typical relative retention time of methylparaben and propylparaben with respect to nizatidine were 1.38 and 2.58 , respectively.

\section{Validation of the method}

The proposed method was validated by determining its performance characteristics regarding specificity, accuracy, precision, limit of detection and quantification, linearity, range and robustness. ${ }^{18,19}$

\section{System suitability}

System suitability shall be checked for the conformance of suitability and reproducibility of chromatographic system for analysis. System suitability was determined before sample analysis from five replicate injections of the standard solution containing 120, 14.4 and $1.6 \mu \mathrm{g} \mathrm{mL}^{-1}$ of nizatidine, methylparaben and propylparaben, respectively. The acceptance criteria were less than $2 \%$ relative standard 

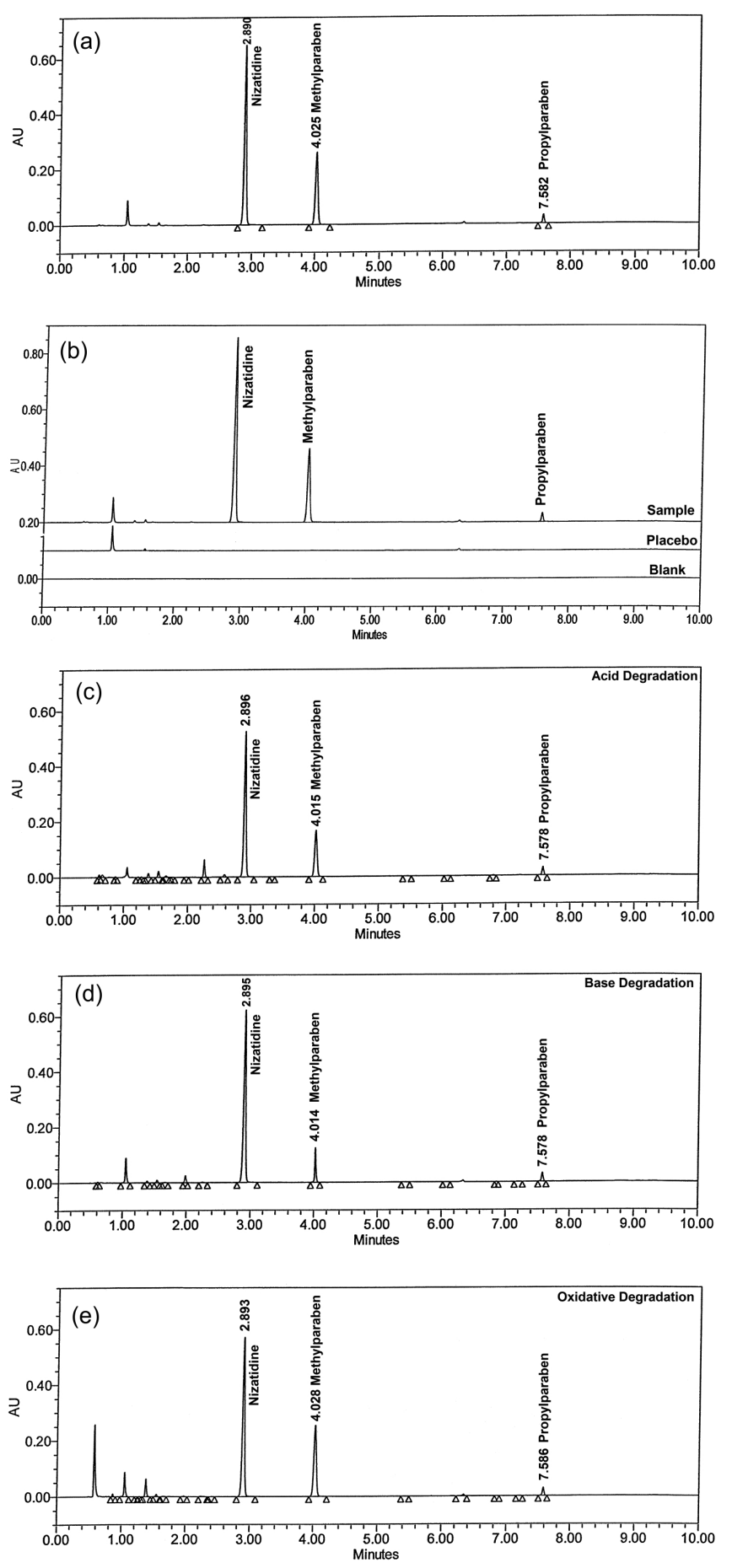

Figure 2. Typical chromatograms of (a) sample preparation, (b) overlay chromatograms of blank, placebo and sample (c) acid degradation sample treated with $1 \mathrm{Mol} \mathrm{L}{ }^{-1} \mathrm{HCl}$ at $60^{\circ} \mathrm{C}$ for $2 \mathrm{~h}$, (d) base degradation sample treated $1 \mathrm{Mol}$ $L^{-1} \mathrm{NaOH}$ at $60^{\circ} \mathrm{C}$ for 15 min and (e) oxidative degradation sample treated with $3 \% \mathrm{H}_{2} \mathrm{O}_{2}$ at room temp for 5 min. Chromatographic conditions: Acquity UPLC $C^{T M}$ HSS T3 (100 x $\left.2.1 \mathrm{~mm}\right) 1.8 \mu \mathrm{m}$ column at $35^{\circ} \mathrm{C}$; mobile phase A: $0.02 \mathrm{Mol} \mathrm{L}^{-1} \mathrm{KH}_{2} \mathrm{PO}_{4}, \mathrm{pH} 7.5$ and mobile phase $\mathrm{B}$ : methanol and acetonitrile $(60: 40 ; \mathrm{v} / \mathrm{v}) ; 0.4 \mathrm{~mL} \mathrm{~min}{ }^{-1}$ of flow rate; gradient program: (time $\left.(\mathrm{min}) / \% \mathrm{~B}\right)$ $0 / 20,1 / 25,5 / 37,7 / 55,8 / 65,8.5 / 65,8.6 / 20$ and 10/20; wavelength of $254 \mathrm{~nm}$

deviation (RSD) for peak areas, USP tailing factor less than 2.0 for nizatidine, methylparaben and propylparaben peaks from standard solution. All critical parameters tested met the acceptance criteria (Table 1).
Table 1. System suitability results of precision and intermediate precision study

\begin{tabular}{lcccc}
\hline \multirow{2}{*}{ Compound } & \multicolumn{2}{c}{ Precision } & \multicolumn{2}{c}{ Intermediate Precision } \\
\cline { 2 - 5 } & $\begin{array}{c}\text { USP Tailing } \\
\leq 2.0\end{array}$ & $\begin{array}{c}\%_{\text {RSD }}{ }^{\text {a }} \\
\leq 2.0\end{array}$ & $\begin{array}{c}\text { USP Tailing } \\
\leq 2.0\end{array}$ & $\begin{array}{c}\text { RSD }^{\text {a }} \\
\leq 2.0\end{array}$ \\
\hline Nizatidine & 1.0 & 0.1 & 1.0 & 0.4 \\
Methylparaben & 1.0 & 0.1 & 1.0 & 0.4 \\
Propylparaben & 1.0 & 0.3 & 1.0 & 0.5 \\
\hline
\end{tabular}

a $\%$ RSD of the analyte peak areas from five replicate injections.

\section{Specificity/stress studies}

Specificity is the ability of the method to measure the analyte response in the presence of its potential degradants and placebo matrix. In the present study, injections of blank and placebo were performed to demonstrate the interference with the elution of nizatidine, methylparaben and propylparaben. These results demonstrate that there was no interference from the other compounds and, therefore, confirms the specificity of the method (Figure $2 b$ ).

Force degradation studies of drug product were also performed to evaluate the stability-indicating property and specificity of proposed method. The solutions of drug product and placebo were exposed to acid hydrolysis $\left(1 \mathrm{Mol} \mathrm{L}^{-1} \mathrm{HCl}\right.$ at $60{ }^{\circ} \mathrm{C}$ for $2 \mathrm{~h}$ ), base hydrolysis ( $1 \mathrm{Mol} \mathrm{L}^{-1} \mathrm{NaOH}$ at $60{ }^{\circ} \mathrm{C}$ for $15 \mathrm{~min}$ ), oxidation ( $3 \% \mathrm{H}_{2} \mathrm{O}_{2}$ at room temperature for $5 \mathrm{~min}$ ), hydrolytic (water at 60 ${ }^{\circ} \mathrm{C}$ for $24 \mathrm{~h}$ ), thermal $\left(105^{\circ} \mathrm{C}\right.$ for $2 \mathrm{~h}$ ) and photolytic degradation (drug product exposed to visible light for $240 \mathrm{~h}$ resulting an overall illustration 1.2 million lux hours and UV light for $250 \mathrm{~h}$ resulting an overall illustration $200 \mathrm{w} \mathrm{h} / \mathrm{m}^{2}$ at $25^{\circ} \mathrm{C}$ ). Significant degradation observed during acid, base hydrolysis and oxidative degradation (Figure 2c-e). Peak purity test was carried out for the nizatidine, methylparaben and propylparaben peaks by using PDA detector in stress samples. The purity of all three substances was unaffected by the presence of degradation products, and, thus confirms the stability-indicating power of the developed method. A summary data of stress study is shown in Table 2.

\section{Limits of detection (LOD) and quantification (LOQ)}

The LOD and LOQ were determined at a signal-to-noise ratio of 3:1 and 10:1, respectively, by injecting a series of dilute solutions with known concentrations. The limit of detection and limit of quantification values are reported in Table 3 .

\section{Linearity}

Linearity test solutions were prepared by diluting the stock solutions to the required concentrations. The solutions were prepared at seven concentration levels from LOQ to $150 \%$ levels of test concentration (LOQ- $180 \mu \mathrm{g} \mathrm{mL}^{-1}$ for nizatidine, LOQ- $21.6 \mu \mathrm{g}$ $\mathrm{mL}^{-1}$ for methylparaben and LOQ- $2.4 \mu \mathrm{g} \mathrm{mL}^{-1}$ for propylparaben). Calibration curves were plotted between the responses of peak versus analyte concentrations. The coefficient correlation, slope, y-intercept of the calibration curve and \% bias at $100 \%$ response are reported (Table 3) and result shows that an excellent correlation existed between peak area and concentration of nizatidine, methylparaben and propylparaben.

\section{Precision}

The precision of method was verified by repeatability and 
Table 2. Summary of forced degradation results

\begin{tabular}{|c|c|c|c|c|c|c|c|}
\hline \multirow{2}{*}{ Stress Condition } & \multicolumn{2}{|c|}{ Nizatidine } & \multicolumn{2}{|c|}{ Methylparaben } & \multicolumn{2}{|c|}{ Propylparaben } & \multirow[t]{2}{*}{$\%$ Degradation } \\
\hline & Purity angle & Purity threshold & Purity angle & Purity threshold & Purity angle & Purity threshold & \\
\hline $\begin{array}{l}\text { Acid hydrolysis }\left(1 \mathrm{Mol} \mathrm{L}^{-1} \mathrm{HCl} \text { at }\right. \\
\left.60^{\circ} \mathrm{C}, 2 \mathrm{~h}\right)\end{array}$ & 0.054 & 0.297 & 0.074 & 0.302 & 0.480 & 0.774 & 5.6 \\
\hline $\begin{array}{l}\text { Base hydrolysis }\left(1 \mathrm{Mol} \mathrm{L}^{-1} \mathrm{NaOH} \text { at }\right. \\
\left.60{ }^{\circ} \mathrm{C}, 15 \mathrm{~min}\right)\end{array}$ & 0.075 & 0.344 & 0.058 & 0.288 & 0.453 & 0.819 & 4.3 \\
\hline $\begin{array}{l}\text { Oxidation }\left(3 \% \mathrm{H}_{2} \mathrm{O}_{2} \text { at room temp, }\right. \\
5 \mathrm{~min})\end{array}$ & 0.058 & 0.315 & 0.057 & 0.296 & 0.479 & 0.851 & 3.2 \\
\hline Thermal (At $105^{\circ} \mathrm{C}, 3 \mathrm{~h}$ ) & 0.075 & 0.337 & 0.065 & 0.295 & 0.432 & 0.792 & 2.5 \\
\hline Hydrolytic (Water at $60^{\circ} \mathrm{C}, 24 \mathrm{~h}$ ) & 0.082 & 0.362 & 0.054 & 0.283 & 0.420 & 0.759 & 1.9 \\
\hline $\begin{array}{l}\text { Photolytic ( } 1.2 \mathrm{million} \text { lux h visible } \\
\text { light and } 200 \mathrm{wh} / \mathrm{m}^{2} \mathrm{UV} \text { light) }\end{array}$ & 0.078 & 0.366 & 0.065 & 0.284 & 0.405 & 0.718 & 2.0 \\
\hline
\end{tabular}

Table 3. Evaluation of LOD, LOQ and linearity data

\begin{tabular}{lccc}
\hline Parameter & Nizatidine & Methylparaben & Propylparaben \\
\hline LOD $(\mu \mathrm{g} / \mathrm{mL})$ & 0.114 & 0.037 & 0.023 \\
LOQ $(\mu \mathrm{g} / \mathrm{mL})$ & 0.341 & 0.110 & 0.068 \\
Correlation coefficient & 0.999 & 0.999 & 0.999 \\
Intercept (a) & -2690.50 & -1833.67 & -1646.63 \\
Slope (b) & 13230.42 & 46662.43 & 38332.67 \\
Bias at 100\% response & 0.0 & 0.0 & -0.3 \\
\hline
\end{tabular}

intermediate precision. Repeatability was checked by injecting six individual preparations of nizatidine oral solution containing nizatidine, methylparaben and propylparaben at 10, 100 and $125 \%$ level of test concentration $\left(11.9,119.3,149.1 \mu \mathrm{g} \mathrm{mL} \mathrm{L}^{-1}\right.$ for nizatidine, $1.45,14.5,18.1 \mu \mathrm{g} \mathrm{mL}{ }^{-1}$ for methylparaben, $0.16,1.6,2.0 \mu \mathrm{g} \mathrm{mL}{ }^{-1}$ for propylparaben). The intermediate precision of the method was also evaluated using different analyst and different instrument and performing the analysis on different days. The relative standard deviation of the areas of each peak was calculated and found to less than $0.9 \%$ in repeatability and less than $0.7 \%$ in intermediate precision, which confirms the good precision of the method. The \%RSD values are presented in Table 4.

Table 4. Precision results determined during method validation

\begin{tabular}{lcccc}
\hline \multirow{2}{*}{ Parameter } & \begin{tabular}{c} 
Amount $^{\text {smiked }}$ \\
\cline { 3 - 5 }
\end{tabular} & \multicolumn{3}{c}{ \% RSD (n=6) } \\
\hline Repeatability & $10 \%$ & 0.3 & 0.3 & 0.9 \\
& $100 \%$ & 0.1 & 0.1 & 0.7 \\
& $125 \%$ & 0.2 & 0.2 & 0.5 \\
Intermediate & $10 \%$ & 0.3 & 0.2 & 0.7 \\
Precision & $100 \%$ & 0.1 & 0.1 & 0.2 \\
& $125 \%$ & 0.1 & 0.1 & 0.5 \\
\hline
\end{tabular}

${ }^{a}$ Amount of all three analyte spiked with respect to target concentration.

\section{Accuracy}

Accuracy of the method for nizatidine, methylparaben and propylparaben was evaluated in triplicate at 10, 50, 100 and $125 \%$ level of test concentration $(11.9,59.7,119.3,149.1 \mu \mathrm{g} \mathrm{mL}-1$ for nizatidine, $1.45,7.25,14.5,18.1 \mu \mathrm{g} \mathrm{mL}^{-1}$ for methylparaben, $0.16,0.8,1.6,2.0$ $\mu \mathrm{g} \mathrm{mL} \mathrm{m}^{-1}$ for propylparaben). The percentage recoveries for all three components were calculated (Table 5). The percentage mean recovery of nizatidine, methylparaben and propylparaben from the formulation varied from 98.8 to $101.2 \%$ indicating that the developed method was accurate for the determination of nizatidine, methylparaben and propylparaben in pharmaceutical formulation.

Table 5. Recovery results determined during method validation

\begin{tabular}{cccc}
\hline \multirow{2}{*}{$\begin{array}{c}\text { Amount } \\
\text { spiked }^{\mathrm{a}}\end{array}$} & \multicolumn{3}{c}{ \% Recovery $^{\mathrm{b}}$} \\
\cline { 2 - 4 } & Nizatidine & Methylparaben & Propylparaben \\
\hline $10 \%$ & $99.1 \pm 0.2$ & $101.2 \pm 0.1$ & $99.5 \pm 0.8$ \\
$50 \%$ & $98.9 \pm 0.1$ & $99.2 \pm 0.1$ & $100.1 \pm 0.2$ \\
$100 \%$ & $99.7 \pm 0.2$ & $100.2 \pm 0.2$ & $99.1 \pm 0.9$ \\
$125 \%$ & $100.4 \pm 0.1$ & $99.7 \pm 0.2$ & $98.8 \pm 0.3$ \\
\hline
\end{tabular}

${ }^{\mathrm{a}}$ Amount of all three analyte spiked with respect to target concentration. ${ }^{\mathrm{b}}$ Mean $\pm \%$ RSD for three determinations

\section{Robustness}

The robustness of the method was evaluated during development by making small, but deliberate, changes to the method parameters. An experiment design was used to determine how changes in colu$\mathrm{mn}$ temperature, flow rate and mobile phase composition affect the chromatography of nizatidine, methylparaben and propylparaben. As shown in Table 6, four factors were evaluated at two levels each. A solution containing $120,14.4$ and $1.6 \mu \mathrm{g} \mathrm{mL}^{-1}$ of nizatidine, methylparaben and propylparaben, respectively, was assayed according to the experimental conditions listed in Table-5. All of the experimental conditions yielded acceptable results (Table 7).

Table 6. Conditions for the robustness study

\begin{tabular}{lccc}
\hline \multirow{2}{*}{ Factor } & \multicolumn{3}{c}{ Level } \\
\cline { 2 - 4 } & Low (-) & Nominal & High $(+)$ \\
\hline $\mathrm{pH}$ & 7.3 & 7.5 & 7.7 \\
$\mathrm{MeOH}(\%)$ & 57.5 & 60 & 62.3 \\
Flow rate $\left(\mathrm{mL} \mathrm{min}^{-1}\right)$ & 0.36 & 0.40 & 0.44 \\
Column temperature $\left({ }^{\circ} \mathrm{C}\right)$ & 30 & 35 & 40 \\
\hline
\end{tabular}

\section{Stability of analytical solution}

The solution stability of nizatidine, methylparaben and propylparaben in the assay method was investigated by leaving sample test solutions in tightly capped volumetric flask at room temperature for $24 \mathrm{~h}$. The same sample solutions were analysed at the end of the study period against freshly prepared standard solutions. The variability in 
Table 7. Robustness results of UPLC method

\begin{tabular}{|c|c|c|c|c|c|c|c|c|c|c|c|c|c|}
\hline \multirow{2}{*}{$\begin{array}{c}\text { Expt. } \\
\text { No. }\end{array}$} & \multirow{2}{*}{$\mathrm{ABCD}^{\mathrm{a}}$} & \multicolumn{4}{|c|}{ Nizatidine } & \multicolumn{4}{|c|}{ Methylparaben } & \multicolumn{4}{|c|}{ Propylparaben } \\
\hline & & $t_{R}^{\mathrm{b}}$ & $A^{\mathrm{c}}$ & $T^{\mathrm{d}}$ & $K^{\mathrm{e}}$ & $t_{R}$ & $A$ & $T$ & $K$ & $t_{R}$ & $A$ & $T$ & $K$ \\
\hline 1 & Nominal & 2.89 & 0.1 & 1.0 & 1.89 & 4.02 & 0.1 & 1.0 & 3.02 & 7.58 & 0.3 & 1.0 & 6.58 \\
\hline 2 & ++++ & 2.71 & 0.1 & 1.1 & 1.72 & 3.24 & 0.2 & 1.1 & 2.26 & 6.99 & 1.3 & 1.0 & 6.01 \\
\hline 3 & -+-+ & 3.28 & 0.1 & 1.0 & 2.28 & 4.49 & 0.0 & 1.0 & 3.48 & 7.90 & 0.2 & 1.0 & 6.90 \\
\hline 4 & --+- & 3.08 & 0.4 & 1.0 & 2.05 & 4.75 & 0.5 & 1.0 & 3.72 & 7.93 & 0.8 & 1.0 & 6.93 \\
\hline 5 & -++- & 3.31 & 0.5 & 1.1 & 2.29 & 4.98 & 0.6 & 1.0 & 3.94 & 8.06 & 1.1 & 1.0 & 7.04 \\
\hline 6 & -+++ & 2.99 & 0.1 & 1.1 & 2.00 & 4.20 & 0.1 & 1.1 & 3.21 & 7.66 & 0.2 & 1.1 & 6.67 \\
\hline 7 & -+-- & 3.55 & 0.1 & 1.0 & 2.51 & 5.35 & 0.0 & 1.0 & 4.27 & 8.31 & 0.8 & 1.0 & 7.29 \\
\hline 8 & ++-- & 4.40 & 1.6 & 0.9 & 3.11 & 5.82 & 1.5 & 0.9 & 4.51 & 8.50 & 1.3 & 0.9 & 7.40 \\
\hline 9 & ---+ & 4.52 & 0.5 & 0.9 & 3.47 & 6.16 & 0.9 & 0.9 & 5.11 & 8.59 & 1.3 & 0.9 & 7.59 \\
\hline 10 & +-++ & 2.69 & 0.1 & 1.0 & 1.69 & 3.30 & 0.1 & 1.0 & 2.30 & 7.01 & 0.3 & 1.0 & 6.01 \\
\hline 11 & ++-+ & 3.26 & 0.0 & 0.9 & 2.26 & 3.96 & 0.1 & 1.0 & 2.96 & 7.54 & 0.4 & 1.0 & 6.57 \\
\hline 12 & +--+ & 3.11 & 0.1 & 0.9 & 2.11 & 3.84 & 0.1 & 1.0 & 2.84 & 7.47 & 0.5 & 1.0 & 6.48 \\
\hline 13 & +--- & 3.19 & 0.1 & 1.0 & 2.19 & 4.33 & 0.7 & 1.1 & 3.30 & 7.79 & 1.5 & 1.0 & 6.78 \\
\hline 14 & +++- & 2.90 & 0.1 & 1.1 & 1.91 & 3.83 & 0.1 & 1.4 & 2.82 & 7.42 & 0.3 & 1.3 & 6.42 \\
\hline 15 & --++ & 2.63 & 0.1 & 1.4 & 1.63 & 3.64 & 0.1 & 1.5 & 2.65 & 7.27 & 0.5 & 1.5 & 6.28 \\
\hline 16 & +-+- & 3.42 & 0.2 & 1.3 & 2.40 & 5.06 & 0.1 & 1.4 & 4.00 & 8.11 & 0.8 & 1.3 & 7.09 \\
\hline 17 & $-\ldots$ & 4.63 & 0.1 & 1.5 & 3.56 & 6.25 & 0.3 & 1.4 & 5.18 & 8.64 & 0.6 & 1.4 & 7.62 \\
\hline
\end{tabular}

${ }^{\mathrm{a}} \mathrm{A}, \mathrm{pH} ; \mathrm{B}, \mathrm{MeOH}(\%)$; C, Flow rate $\left(\mathrm{mL} \mathrm{min}^{-1}\right)$; D, Column Temperature $\left({ }^{\circ} \mathrm{C}\right) .{ }^{b}$ Retention time (min) of the analyte peak. ${ }^{\mathrm{c}} \%$ RSD of the analyte peak areas from 5 injections. ${ }^{\mathrm{d}}$ Tailing factor of the analyte peak. ${ }^{\mathrm{e}}$ Capacity factor of the analyte peak

the assay of all three substances was within $\pm 3 \%$ during solution stability. The results from solution stability experiments confirmed that sample solution and standard solutions were stable up to $24 \mathrm{~h}$.

\section{CONCLUSIONS}

A simple and efficient reverse-phase UPLC method was developed and validated for quantitative analysis of nizatidine, methylparaben and propylparaben in pharmaceutical dosage forms. The method found to be precise, accurate, linear, robust and rugged during validation. Satisfactory results were obtained from the validation of the method. The method is stability indicating and can be used for routine analysis of production samples and to check the stability of the nizatidine oral solution.

\section{ACKNOWLEDGEMENT}

The authors are thankful to the management of Dr. Reddy's Laboratories Ltd., Hyderabad for providing facilities to carry out this work.

\section{REFERENCES}

1. http://www.rxlist.com/axid_oral_solution-drug.htm, accessed July 2011.

2. Rieger, M. M.; Handbook of pharmaceutical excipients, $2^{\text {nd }}$ ed., The pharmaceutical press: London, 1994.

3. Department of Health, Government of India; Appendix IX, Stability testing of new drugs, Drug and cosmetics act and rules, 1940, p. 540.

4. ICH Q6A; Specifications: Test procedures and acceptance criteria for new drug substances and new drug products: Chemical substances, International Conference on Harmonization, 1999.
5. Yusuf, A.; Al Dgither, S.; Hammami, M. M.; Ther. Drug Monti. 2006, $28,232$.

6. Tracqui, A.; Kintz, P.; Mangin, P.; J. Chromatogr. Biomed. Appl. 1990, $529,369$.

7. Imre, S.; Vlase, L.; Leucuta. S. E.; Rev. Roum. Chim. 2007, 52, 261.

8. Ashiru, D. A. I.; Patel, R.; Basit, A. W.; J. Chromatogr., B: Anal Technol. Biomed. Life Sci. 2007, 860, 235.

9. Ho, C.; Huang, H. M.; Hus, S. Y.; Shaw, C. Y.; Chang, B. L.; Drug Dev. Ind. Pharm. 1999, 25, 379.

10. Gomes, A. R.; Raghuram, P.; Sriramulu, J.; Srinivas, N.; Am. J. Anal. Chem. 2011, 2, 314

11. The United States Pharmacopoeia, $34^{\text {th }}$ ed., The United States Pharmacopoeial Convention: Rockville, 2011.

12. European Pharmacopoeia 4.2, Council of Europe, 2002.

13. Hajkova, R.; Solich, P.; Dvoiak, J.; J. Pharm. Biomed. Anal. 2003, 32, 921.

14. Seong, K.; Hasuck, K.; J. Pharm. Biomed. Anal. 1997, 15, 1359.

15. Diane, K.; Bela, K.; J. Chromatogr., B: Anal. Technol. Biomed. Life Sci. 1998, 707, 181.

16. Mangus, A.; Atemnkeng, E. M.; Jacqueline, P.; J. Pharm. Biomed. Anal. 2007, 43, 727 .

17. Petruci, J. F. S.; Cardoso, A. A.; Pereira, E. A.; Quim. Nova 2011, 34, 1177.

18. ICH Q2 (R1); Validation of Analytical Procedures: Text and Methodology, International Conference on Harmonization, 2005.

19. ICH Q1A (R2); Stability Testing of new Drug Substances and Products, International Conference on Harmonization, 2003. 